\title{
Multi-walled carbon nanotubes change morpho-functional and GABA characteristics of mouse cortical astrocytes
}

\author{
Joo-Ok Min ${ }^{1 \dagger}$, Seong Yeol Kim ${ }^{1,2 \dagger}$, Ueon Sang Shin ${ }^{1,2^{*}}$ and Bo-Eun Yoon ${ }^{1 *}$
}

\begin{abstract}
Background: Multi-walled carbon nanotubes (MW-CNTs) have been extensively explored for their possible beneficial use in the nervous system. CNTs have shown to modulate neuronal growth and electrical properties, but its effect that varying length of MW-CNTs on primary astrocyte roles have not been clearly demonstrated yet.

Results: We investigate here the effect of MW-CNTs on astrocytic morphology, cell-cell interaction and the distribution of intracellular GABA (gamma-amino butyric acid). Primary cultured cortical astrocytes on MW-CNT-coated glass coverslips grow rounder and make more cell-cell interactions, with many cell processes, compared to astrocytes on poly-D-lysine (PDL) coverslips. In addition, intracellular GABA spreads into the cell processes of astrocytes on MW-CNT coverslips. When this GABA spreads into cell processes from the cell body GABA can be released more easily and in larger quantities compared to astrocytes on PDL coverslips.
\end{abstract}

Conclusions: Our result confirm that MW-CNTs modulate astrocytic morphology, the distribution of astrocytic GABA, cell-cell interactions and the extension of cell processes. CNTs look to be a promising material for use neuroprosthetics such as brain-machine interface technologies.

Keywords: Multi-walled CNT, Astrocytes, GABA

\section{Background}

Nanotechnology is an emerging and fast growing field with, encouraging prospects that may revolutionize many disciplines such as engineering, biology, chemistry, physics and medicine [1]. Carbon nanotubes (CNTs) are hollow cylinders made of graphene sheets rolled in on themselves to form a tube [2]. They are categorized based on the number of carbon layers assembled together: single-walled (SW-CNTs), double-walled (DW-CNTs), and multi-walled (MW-CNTs) [3]. MW-CNTs consist of multiple concentrically rolled layers of graphene. Depending on the number of layers, the inner diameter of MW-CNTs varies from $0.4 \mathrm{~nm}$ to a few nanometers

\footnotetext{
*Correspondence: usshin12@dankook.ac.kr; boeunyoon@dankook.ac.kr ${ }^{\dagger}$ Joo-Ok Min and Seong Yeol Kim contributed equally to this work 1 Department of Nanobiomedical Science and BK21 PLUS NBM Global Research Center for Regenerative Medicine, Dankook University, Dandae-ro, Dongnam-gu, Cheonan-si, Chungnam 330-714, Republic of Korea

Full list of author information is available at the end of the article
}

and the outer diameter varies characteristically from $2 \mathrm{~nm}$ to $20-30 \mathrm{~nm}$ [4]. The advantages of MW-CNTs over single-walled nanotubes include ease of mass production, a lower product cost per unit and a higher tensile strength $[5,6]$.

CNTs have been extensively explored for their beneficial use in nervous system tissue engineering, such as in CNT-based nerve scaffolds to drive nerve regeneration across a lesion site [2]. CNTs have shown much promise in neural applications $[7,8]$. CNT planar strata were shown to modulate neuronal growth and neurite outgrowth in culture and can affect the electrical properties of neurons, effects that appear to sprout from electrical shortcuts, that is direct physical interactions between the CNTs embedded within the film and the neurons grown on it [9]. Indeed, over a narrow range of thicknesses, the CNT layers can affect the outgrowth of neurites, the number of growth cones, and the neuronal body area [10]. 
In addition, recent studies suggest that glia cooperate closely with neurons and actively participate in the regulation of synaptic transmission. Among the various types of glia, astrocytes make direct contact with neurons, forming tripartite synapses, where astrocytic processes are in close association with the presynapse and postsynapse at the synaptic junction [11, 12]. Astrocytes express diverse receptors for the corresponding neurotransmitters and release various gliotranmitters and neuroactive molecules [13-15].

It has been shown recently that effects of diverse nanostructures on glial cells. For instance, impaired autophagy flux in primary glial cells in Alzheimer's disease mouse model promotes disease progression. Functionalized single-walled carbon nanotubes (SW-CNTs) restored normal autophagy by facilitating elimination of autophagic substrates [16]. SW-CNT-net can be used as growth substrate for astrocytes and label-freely detects local ATP release from these cells [17]. A number of studies demonstrated that CNTs are beneficial materials in neuron and neural stem cells, such as CNTs boost neuronal electrical signaling [18], direct stem cell differentication toward neural lineages [19] and control neurite outgrowth in vitro $[20,21]$. Over a narrow range of thicknesses $(10,30,60 \mathrm{~nm})$ single-walled carbon nanotube films modulate the round morphology and increase the relative density of living cells [22]. However, the effect that varying length MW-CNTs on coated coverslips have on primary astrocytes is not understood. Therefore, we selected MW-CNTs of the most proliferative length $(50 \mathrm{~nm})[22,23]$ and of those of long length $(1000 \mathrm{~nm})$ in order to investigate the effect of CNT. In this study, we evaluated MW-CNT cytotoxicity and cell-cell interaction. Furthermore, we investigated the distribution of astrocytic GABA, the major inhibitory neurotransmitter that has recently been reported to mediate tonic inhibition from glia [24].

\section{Methods}

Materials

Pristine MW-CNTs (>95 \%, 15-20 nm outer diameter, $10-20 \mu \mathrm{m}$ length, $p$-CNTs) were purchased from EMP (EM-Power Co., LTD, Korea). 3-aminopropyltriethoxysilane (APTES) and 1-ethyl-3-(3-dimethylaminopropyl) carbodiimide (EDC) were purchased from SigmaAldrich (USA). All supplementary chemicals were of analytical grades and used without further purification. Coverslips (12 $\mathrm{mm}$ diameter) were purchased from Marienfeld (Germany).

\section{Animals}

P0-P2 Balb/c mice were used for primary astrocyte cultures. All experimental procedures described below were performed in accordance with the Dankook University Animal Experimentation Guidelines (Cheonan, Korea).

Preparation of highly water-soluble multi-walled carbon nanotubes (MW-CNTs of lengths $\sim 50$ and $\sim 1000 \mathrm{~nm}$ )

Highly water-soluble, carboxyl group functionalized multi-walled carbon nanotubes (MW-CNT-COOH of lengths $\sim 50$ and $\sim 1000 \mathrm{~nm}$ (MW-CNT-50 and -1000) were prepared using the acid oxidative method and a homogenizer (NanoDeBee 45-3, Bee International). Typically, $2 \mathrm{~g}$ of pristine-CNTs ( $p$-CNTs) were added to $100 \mathrm{~mL}$ of a concentrated $1: 1 \mathrm{H}_{2} \mathrm{SO}_{4} / \mathrm{HNO}_{3}$ solution and refluxed at $80{ }^{\circ} \mathrm{C}$ for 4 days. The mixture obtained was diluted with $100 \mathrm{~mL}$ of distilled water and then filtered through a $0.4 \mu \mathrm{m}$ Millipore polycarbonate filter membrane. The resulting MW-CNT powders (average length $\sim 1000 \mathrm{~nm}$ ) were then continuously washed with distilled water until the filtrate $\mathrm{pH}$ reached 7. The MW-CNT-1000 obtained was further cut using the NanoDeBee process (5 cycles) to obtain MW-CNT-50 having a length of $\sim 50 \mathrm{~nm}$.

\section{Immobilization of MW-CNT-50 and MW-CNT-1000 on a glass substrate}

Prior to use, the glass $\left(\mathrm{SiO}_{2}\right)$ substrates (coverslips) were ultrasonically cleaned in deionized water, acetone and ethanol. To prepare carbon nanotube layers on the precleaned $\mathrm{SiO}_{2}$ substrates, the amine functionalized coverslips were initially treated with APTES. Coverslips were allowed to react with $10 \mathrm{w} / \mathrm{v} \%$ of APTES in distilled water containing hydrochloric acid $(\mathrm{pH}=3$; adjusted with $2 \mathrm{~N} \mathrm{HCl}$ ) at $80^{\circ} \mathrm{C}$ for $10 \mathrm{~min}$. They were then rinsed with distilled water and dried at $110{ }^{\circ} \mathrm{C}$. This process was repeated a further 4 times (totalling 5times). The amine functionalized coverslips $(\times 5)$ were soaked in $1.5 \mathrm{~mL}$ of $0.1 \mathrm{w} / \mathrm{v} \%$ aqueous CNT solution in the presence of EDC and $\mathrm{HCl}(\mathrm{pH}=5$; adjusted with $1 \mathrm{~N} \mathrm{HCl})$ by shaking at room temperature (RT) for $3 \mathrm{~h}$. They were then rinsed with distilled water and ethanol and let it dried in the air. The mono-layered CNT coating was confirmed using SEM microscopy as shown in Fig. 1e-h.

\section{Characterizations}

The mean sizes of the prepared MW-CNTs were measured at room temperature (RT) with a Zeta sizer Nano ZS90 (Malvern, France) in aqueous solution and by field emission scanning electron microscopy (FE-SEM; MIRA II LMH, Tescan, Czech Republic). The surface morphologies of coverslips modified with the MW-CNT samples were also observed by FE-SEM. The specimens for FE-SEM analysis were subjected without coating with gold prior to examination. The dispersion stabilities of MW-CNT samples were tested using a Turbiscane Lab 
(Leanontech, France) in PBS solution at RT for about $1.5 \mathrm{~h}$ and measuring the backscattered light of a pulsed near infrared light source of wavelength $880 \mathrm{~nm}$. Qualitative and quantitative analyses of MW-CNT samples were performed by Fourier-transform infrared (FT-IR) spectrometry and thermogravimetric analysis (TGA).

\section{Primary cortical astrocyte cultures}

The cerebral cortex from P0 to P2 in postnatal Balb/c mice was dissected free of adherent meninges, minced and dissociated into a single-cell suspension by trituration. Then single-cell suspension cultured on coated poly-D-lysine culture dish. After 3 days, cell debris and medium were removed then fresh medium were added. 4 days after removing cell debris, cells were suspended using $0.05 \%$ trypsin and cells were counted with a hematocytometer. Dissociated $2 \times 10^{5}$ cells were plated onto $12-\mathrm{mm}$ glass coverslips coated with $0.05 \mathrm{mg} / \mathrm{ml}$ multiwalled CNT or $0.1 \mathrm{mg} / \mathrm{ml}$ poly-D-lysine. Cells were grown in Dulbecco's modified Eagle's medium (DMEM) supplemented with $25 \mathrm{mM}$ glucose, $10 \%$ heat-inactivated horse serum, $10 \%$ heat-inactivated fetal bovine serum, $2 \mathrm{mM}$ glutamine, and $1 \%$ penicillin-streptomycin. Cultures were maintained at $37{ }^{\circ} \mathrm{C}$ in a humidified atmosphere containing $5 \% \mathrm{CO}_{2}$.

\section{Scanning electron microscope}

Primary cortical astrocytes are seeded on MW-CNT and PDL coverslips after 1 day and 4 days, after which the medium was removed and cells were washed once in $0.1 \mathrm{M}$ phosphate buffered saline (PBS). After washing, astrocytes were fixed for 5 min in $2 \%$ glutaraldehyde. For each coverslip type, cells were dehydrated for $5 \mathrm{~min}$ in $70 \%$ ethanol and $90 \%$ ethanol. Then cells were dehydrated twice in $100 \%$ ethanol and incubated for $1 \mathrm{~min}$ in hexamethyldisilazane. Cells on each coverslip type were dried overnight at RT. After drying, astrocytes on both coverslip types were coated with platinum for $80 \mathrm{~s}$. A series of images was obtained with a field emission scanning electron microscope (Hitachi). Astrocyte roundness was calculated using image J program. Roundness factor formula is $4 \pi \times\left[\right.$ area $\left(\mu \mathrm{m}^{2}\right) /\left[\right.$ perimeter $\left.\left(\mu \mathrm{m}^{2}\right)\right]$.

\section{Measurement of cell viability and proliferation}

Primary cortical astrocytes were seeded with the number of $2 \times 10^{5}$ cells for 1 day and 4 days and the cytotoxicity of MW-CNT compared to PDL coverslips was measured by adding. Cell Counting Kit-8 (CCK-8; Enzo life science, USA) solution and further incubating coverslips for $3 \mathrm{~h}$. Optical density (OD) was then measured at absorbance wavelength $450 \mathrm{~nm}$ using a Versa Max microplate reader (Molecular Devices, USA). Rates of cell cytotoxicity and proliferation were calculated from the following equation. Cell viability $=($ ODsample - ODblank $)$, where ODblank was obtained from the medium alone.

\section{Immunocytochemistry}

Primary cortical astrocytes seeded on MW-CNT and PDL coverslips were fixed after 4 days in $4 \%$ paraformaldehyde for $30 \mathrm{~min}$ at RT. After fixation, cells were washed three times in $0.1 \mathrm{M}$ phosphate buffered saline (PBS). Cells were incubated for $1 \mathrm{~h}$ at RT with blocking solution (0.3 \% Triton-X, $2 \%$ normal serum in $0.1 \mathrm{M} P B S)$. Then cells were incubated with primary antibody in $0.3 \%$ Triton-X, $2 \%$ normal serum in 0.1 M PBS, overnight at $4{ }^{\circ} \mathrm{C}$ on a shaker; Guinea pig anti-GABA antibody 1:400 (Millipore Bioscience Research), Chicken anti-GFAP antibody 1:500 (Millipore Bioscience Research). After washing three times in PBS, cells were incubated with the corresponding secondary antibodies; conjugated Alexa 647 Goat anti Guinea-pig antibody (1:200; Jackson ImmunoResearch Inc.), conjugated Alexa 488 Donkey anti-Chicken antibody (1:200; Jackson ImmunoResearch Inc.), for $2 \mathrm{~h}$, followed by one rinse in PBS, and were then incubated one more time in DAPI (1:1000), followed by a further rinse in PBS. Then cells were mounted in fluorescent mounting medium. A series of fluorescence images was obtained with confocal microscopy (Zeiss, LSM 700) and images were processed for later analysis using ZEN 2010 imaging software. GFAP fluorescence intensity was measured using image J and Excel program. GFAP fluorescence intensity was measured following calculation (i.u.). The GFAP fluorescence intensity (i.u.) = cell intensity - (area $\times$ mean fluorescence of background).

\section{Results and discussion}

To generate carbon nanotube layers on coverslips, highly water-soluble and carboxyl group functionalized multiwalled carbon nanotubes ( 50 and $\sim 1000 \mathrm{~nm}$ of length) were initially prepared (Step 1) and then the pre-cleaned $\mathrm{SiO}_{2}$ substrate were functionalized with amine groups via treatment with APTES (Step 2), followed by the immobilization of carboxyl group-functionalized CNTs through amide bond formation (Step 3). Physicochemical characterizations of the prepared MW-CNT samples (MWCNT-50 and MW-CNT-1000) were made in terms of dispersion stability and average particle sizes in aqueous solution, functional groups, and thermal stability, using respectively Turbiscane Lab and Zeta sizer, FT-IR and TGA as shown in Fig. 1.

Unlike pristine CNTs ( $p$-CNTs; see Addtional file 1: Figure S1), no noticeable changes in backscattered light fluxes and transmission were observed, meaning there was a clear surface wettability change from the hydrophobic charateristic of $p$-CNTs to the hydrophilic property of the modified MW-CNTs (Fig. 1a, b). The aqueous 
a

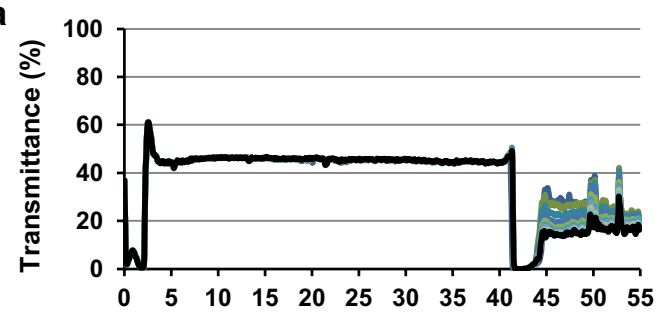

Height $(\mathrm{mm})$

b

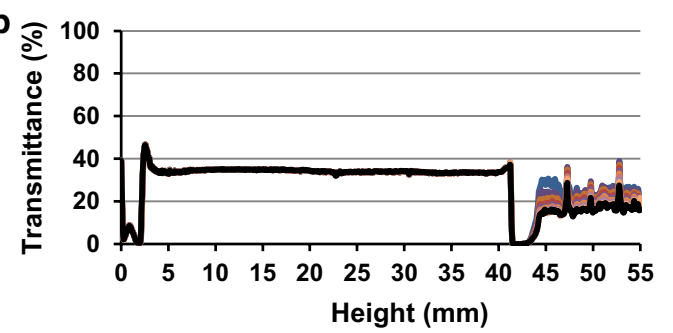

C

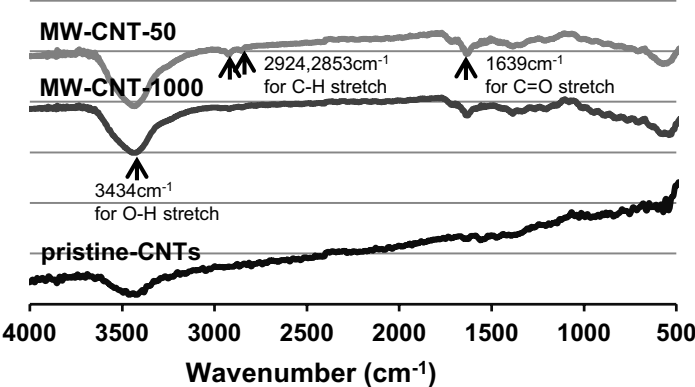

Height (mm)
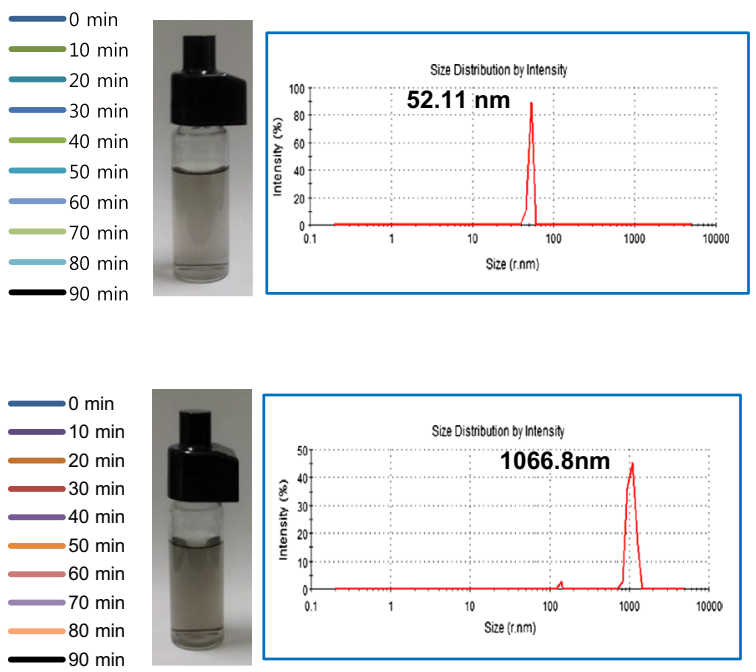
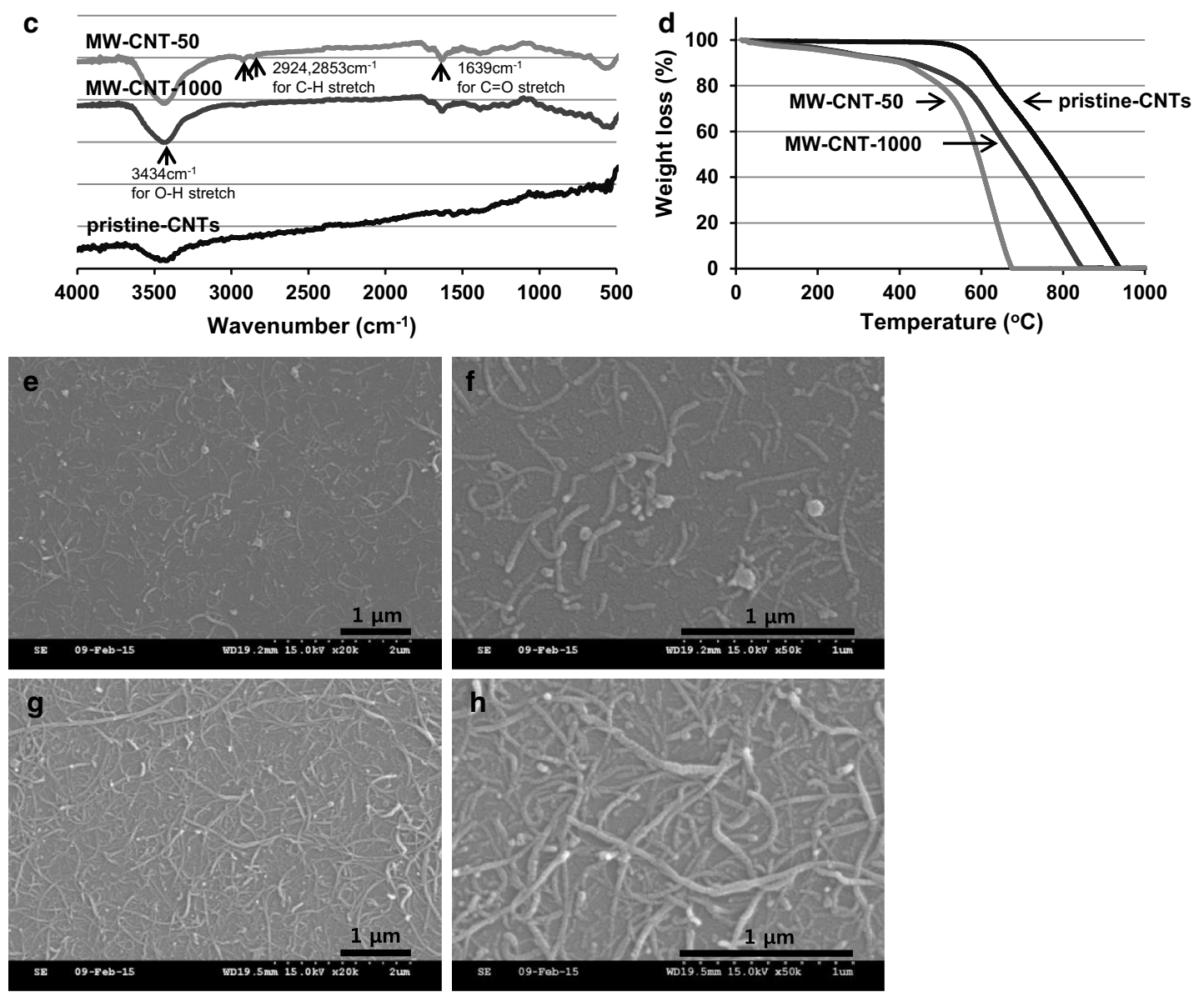

Fig. 1 Characterization of MW-CNT-50 and MW-CNT-1000. a, b show dispersion stability of MW-CNT-50 (a) and MW-CNT-1000 (b) measured in water by Turbiscane Lab: Size distribution curves for MW-CNT-50 and MW-CNT-1000 and a photo of their aqueous solutions $\left(5 \times 10^{-3} \mathrm{mg} / \mathrm{mL}\right)$ homogeneously dispersed in water are shown as insets. $\mathbf{c}$, d show characterizations of $p$-CNTs, MW-CNT-50, and MW-CNT-1000 by FT-IR (c) and TGA (d). e, h h show SEM images of the surface morphology of coverslips uniformly coated with MW-CNTs; MW-CNT-50 (e, f) and MW-CNT-1000 (g, h); this SEM images with lower MW-CNT concentration in e, f were intentionally selected to prove that MW-CNT-50 molecules immobilized on the coverslip have an average length of $50 \mathrm{~nm}$. The full scale SEM images of high magnification for MW-CNT-50 and MW-CNT-1000 samples were provided in Additional file 1: Figure S3 of the supplementary materials to show the similarity of the overall MW-CNT concentration for both samples 
solutions of MW-CNT samples, which have some darkcolor as shown in the inset photos of Fig. 1a, b, were highly homogeneous and nothing was deposited at the bottom of sample bottles even after a period of several days. Observations on the size changes of the prepared MW-CNT samples were conducted under aqueous conditions $\left(1 \times 10^{-4} \mathrm{wt} \%\right)$ by a Zeta sizer. As shown in Fig. 1 insets, the average sizes of MW-CNT samples were recorded to be, respectively, $\sim 50 \mathrm{~nm}$ and $\sim 1000 \mathrm{~nm}$ long. The measured average sizes in length could be confirmed in the SEM images as well, but generally it is hard to measure the accurate length in SEM images, because smaller MW-CNT pieces could be hidden under longer MW-CNT molecules which were congregated in each other (see Additional file 1: Figure S3).

An FT-IR study was performed to characterize the functional groups developed on MW-CNT surfaces (Fig. 1c). The functional groups $(-\mathrm{O}-\mathrm{H},-(\mathrm{C}=\mathrm{O})-$, and $\mathrm{COOH}$ ) as-formed after the functionalization of $p$-CNTs by chemical oxidation were observed clearly in the spectra of MW-CNT samples with average lengths of 50 and $1000 \mathrm{~nm}$, for example, as strong bands at $\sim 3434 \mathrm{~cm}^{-1}$ for the $\mathrm{O}-\mathrm{H}$ stretch, $2924-2853 \mathrm{~cm}^{-1}$ for the $-\mathrm{CH}_{2}-$ stretch, and $1725-1630 \mathrm{~cm}^{-1}$ for the $\mathrm{C}=\mathrm{O}$ stretch, whereas the spectrum of $p$-CNTs showed very weak peaks in the same frequency ranges, demonstrating the intensive functionalization of the $p$-CNT surface with hydrophobic characteristics. Thermo gravimetric analysis (TGA: Fig. 1d) showed that both MW-CNT samples of $\sim 50$ and $\sim 1000 \mathrm{~nm}$ length were slowly decomposed in the initial temperature range of $<\sim 425{ }^{\circ} \mathrm{C}$, followed by an intensive secondary decomposition occurring in the temperature ranges of $\sim 425$ to $\sim 670{ }^{\circ} \mathrm{C}$ for MW-CNT-50 and $\sim 425$ to $\sim 840{ }^{\circ} \mathrm{C}$ for MW-CNT-1000, while the $p$-CNTs showed only an intensive decomposition curve witha steep slope in the temperature range of $\sim 600$ to $\sim 930{ }^{\circ} \mathrm{C}$. It was also clear that the gradual slope increase clearly occurred in accordance with the size reduction. Consequently, the resulting MW-CNTs with characteristics such as $\sim 50$ and $1000 \mathrm{~nm}$ lengths and hydrophilic surfaces could be considered suitable for coating coverslips. After coating the surface of the coverslips with modified MW-CNTs, we examined the morphology changes of the functionalized MW-CNTs and the coverslip surface by SEM. A clear morphology change from aggregates of purchased long carbon nanotubes (about $17 \mu \mathrm{m}$ in length; Additional file 1: Figure S2) to homogenously dispersed nanotubes is evident (Fig. 1e-h). Moreover, the rough surface of MW-CNTs coated on the surface of coverslips clearly indicates the oxidative damage of $p$-CNTs and the formation of hydrophilic functional groups such as $-\mathrm{OH}$ and $-\mathrm{COOH}$ on the MW-CNT surfaces, which may possibly encourage a chemical link such as an amide bond, between the glass coverslip and the MW-CNT surfaces and thus chemically bind MW-CNTs with the glass surface. In stark contrast, the smooth surface and the loose gathering of $p$-CNTs may indicate that only the possible $\pi-\pi$ interaction between $p$-CNT surfaces that have few $-\mathrm{OH}$ and $-\mathrm{COOH}$ functional groups caused the heterogeneous agglomeration (Additional file 1: Figure S2). As shown in Fig. 1e-h, the highly uniform MW-CNTcoating in a monolayer on the coverslip may demonstrate that MW-CNT molecules are closely bound to the glass surface and that the smaller the MW-CNTs are, the more they are coated in monolayer.

Based on observations from scanning electron microscopy, we assessed astrocyte morphology using morphometic parameters (Roundness factor). Roundness factor formula is $4 \pi \times$ [area $\left(\mu \mathrm{m}^{2}\right) /\left[\right.$ perimeter $\left.\left(\mu \mathrm{m}^{2}\right)\right]$. The circularity of circle is 1 , while thin thread is approximately 0 . We found that astrocytes on MW-CNT-50 have a increased shape factor compared to astrocytes on PDL coverslips (Fig. 2a-d, g). Astrocytes on $1000 \mathrm{~nm}$ length MW-CNT coverslips were shown to have a similar shape to those on PDL coverslips (Fig. 2e-f, g). In addition, astrocytes can form gap junctions with neighboring cells, thereby forming interconnected groups of cells sharing a common cytoplasm [25]. Gap junction are classified as a type of intercellular junction with a function in intercellular communication $[26,27]$. Therefore, we suggest that astrocytes on MW-CNTs $(50,1000 \mathrm{~nm})$ have more cellcell interaction, with higher numbers of cell processes compared to those seen on PDL coverslips (Fig. 2h). We determined that MW-CNT differential lengths change the morphology of astrocytes. In particular, MWCNT-50 give a rounder shape than PDL, but they show more cell-cell interactions. A rounder shape does not thus decrease cell-cell interactions, but rather increases the number of cell processes.

To date there is very little known about the potential neurotoxic effects of CNTs. Recent experiments in rat and fish showed that nanosized carbon particles can be taken up by olfactory neurons in the nose and are translocated to the brain, which would seem to make neurotoxicity of CNTs an important issue [28, 29]. Therefore, we evaluated the cytotoxicity of MW-CNTs and the proliferation of primary cortical astrocytes using CCK-8 solution in which viable cells convert WST (water-soluble tetrazolium salt) to formazan using dehydrogenase. WST receives two electrons from viable cells to generate a yellow or orange formazan dye. Formazan was released into the medium and then we measured optical density (Fig. 3a). We measured cell viability and proliferation, after seeding for 1 day and for 4 days. The 1 day period gives an initial astrocyte adhesion on MW-CNT (50, $1000 \mathrm{~nm}$ ) and PDL coverslips and the 4 day period allows 

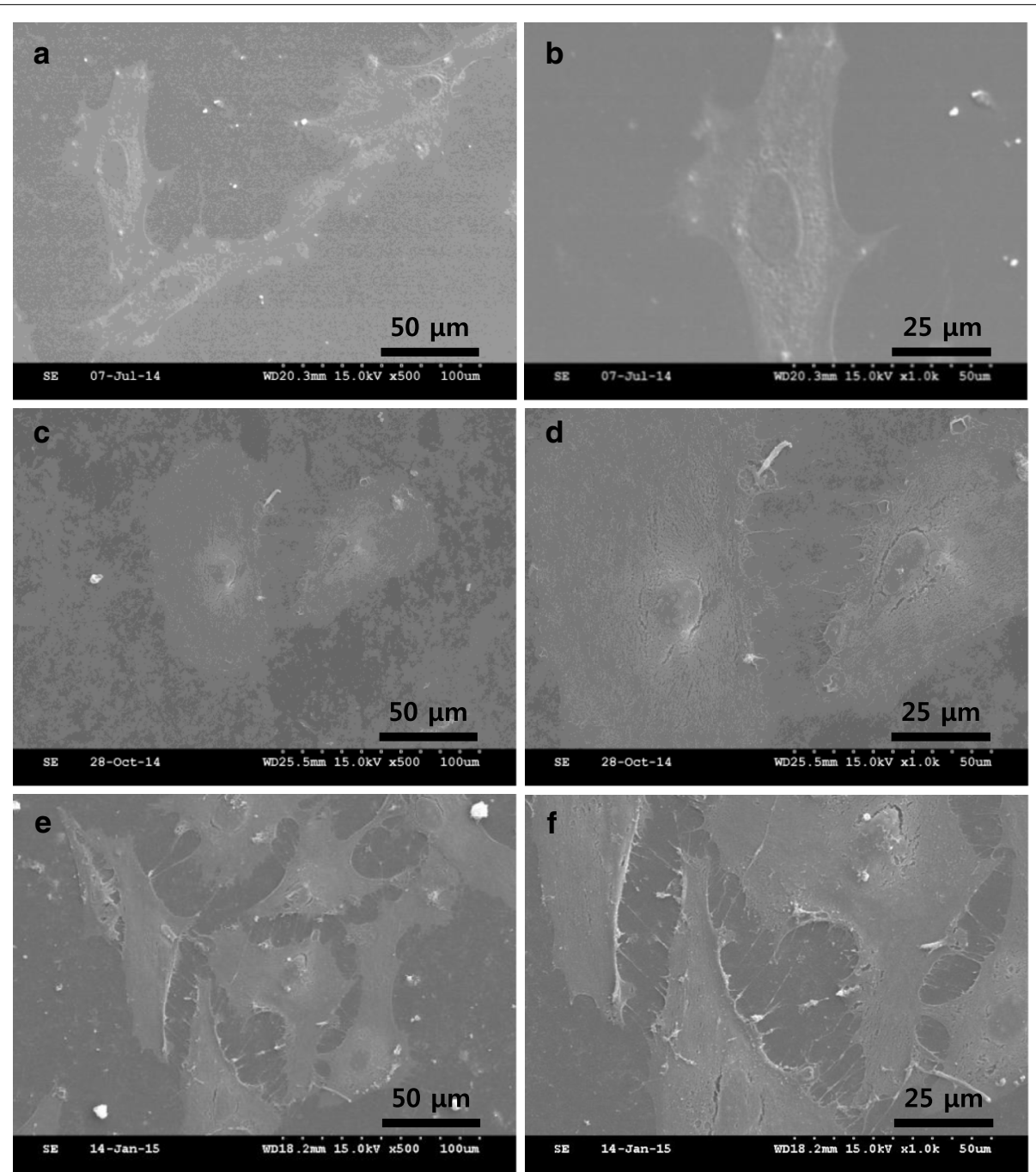

g

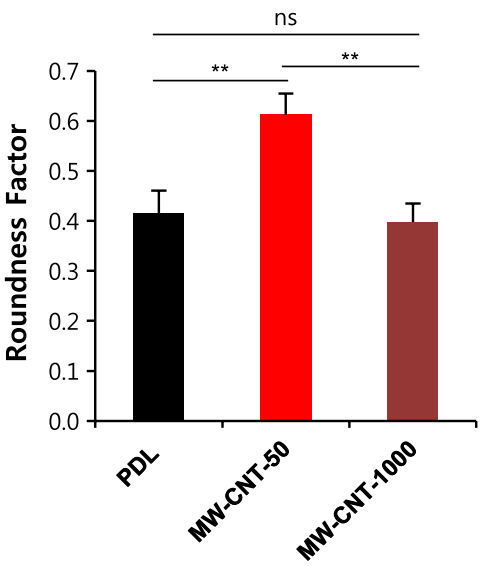

h

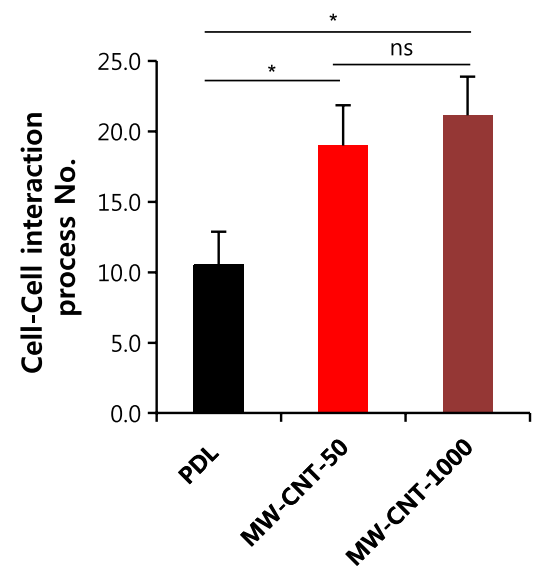

Fig. 2 MW-CNTs affect astrocyte morphology as shown by scanning electron microscopy. a, b show primary cultured cortical astrocytes on PDL coverslips. c, $\mathbf{d}$ show astrocytes on MW-CNT-50 coverslips with much rounder cells. e, $\mathbf{f}$ show astrocytes on MW-CNT-1000, cell growth is similar to that seen on PDL. $\mathbf{g}$ shows roundness parameter graph. Astrocytes on MW-CNT-50 $(n=8)$ showed higher roundness factor compared to astrocytes on PDL $(n=10)$ and MW-CNT-1000 $(n=7)$. Roundness factor formula is $4 \pi \times\left[\right.$ area $\left(\mu m^{2}\right) /\left[\right.$ perimeter $\left.\left(\mu m^{2}\right)\right]$. h graph shows MW-CNTs $(M W-C N T-50$; $\mathrm{n}=8$, MW-CNT-1000; $\mathrm{n}=7$ ) make more cell-cell interactions, with many cell processes, compared to astrocytes on PDL coverslips $(n=10)$; 


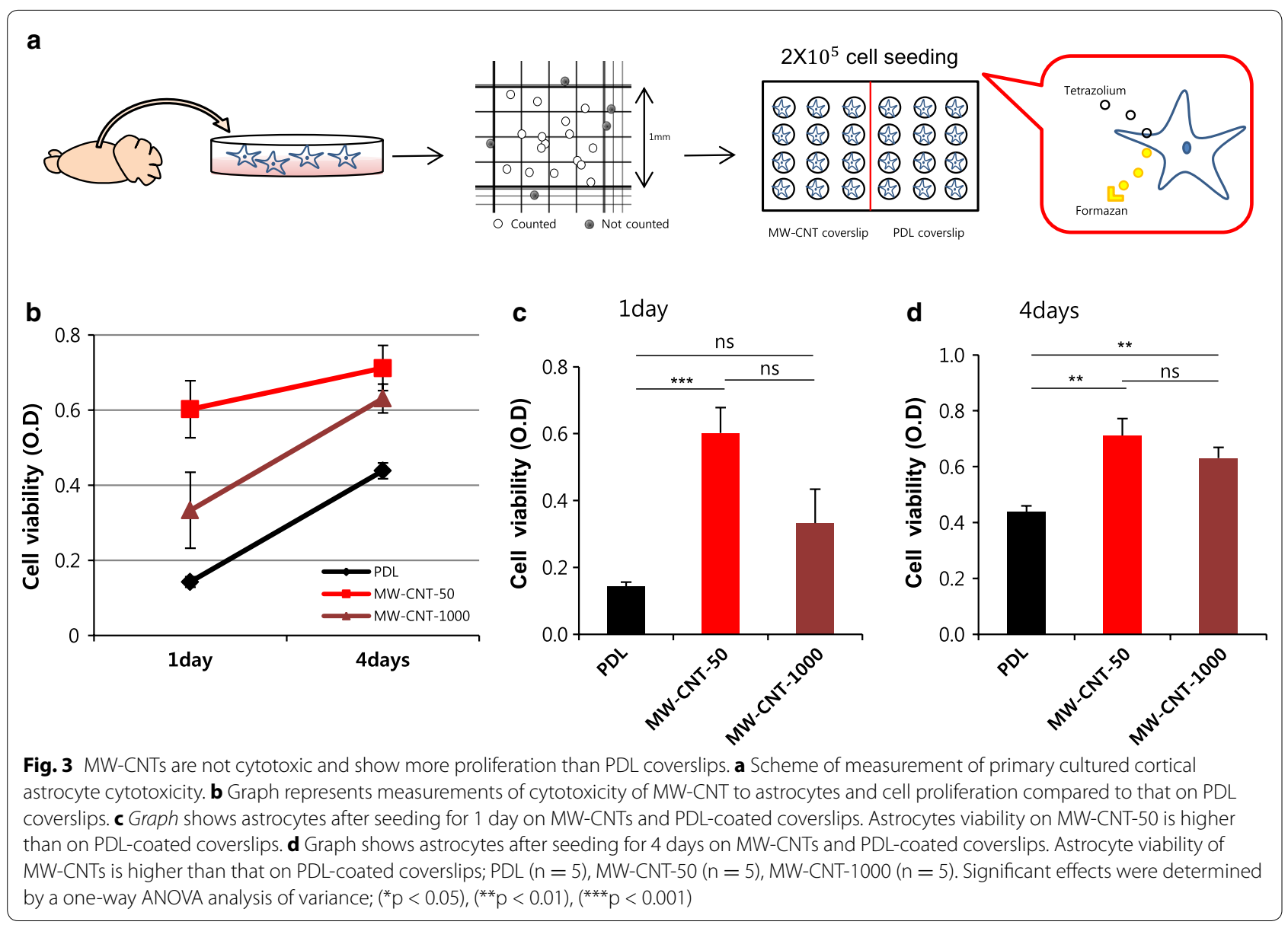

for proliferation of astrocytes seeded on MW-CNT and PDL coverslips. Cytotoxicity of MW-CNT-50 and MWCNT-1000 is not different from astrocytes on PDL coverslips (Fig. 3b-d). After seeding for 1 day, the cell viability of astrocytes on MW-CNT-50 was increased and the relative density of live cells on MW-CNT-50 was fourfold that of cells on PDL. After seeding for 4 days, most of the higher cell viability was observed on the MWCNT-50, while most of the proliferation ratio was measured on MW-CNT-1000 (Fig. 3d). Next, we investigated intracellular GABA distribution on MW-CNT and PDL coverslips. In MW-CNTs, astrocytic GABA spreads into more cell processes than occurs on PDL coverslips, and astrocytes on MW-CNT-50 have a rounder shape, implying that this rounder shape does not affect GABA distribution (Fig. 4). When astrocytic GABA spreads into cell processes from the cell body, GABA can be released more easily and in greater quantities compared to that from astrocytes on PDL coverslips. The diffusional GABA into cell processes accelerates release to tripartite synapses and increases astrocyte-neuron interactions, implying increased bidirectional communication because proteins such as transporters, receptors and channels are involved in neurotransmitter release. In particular, and consistent with SEM imaging, MW-CNT-1000 makes more cellcell interactions (Fig. 4c). Some reports show that the cause of neurodegenerative diseases, such as Parkinson's disease (PD) and Alzheimer's disease (AD), is a progressive loss of structure or function of neurons, as well as neuronal cell death. Also, increased GFAP immunoreactivity decreases tissue damage and neuronal loss and demyelination [30, 31]. Based on our immunocytochemical data, MW-CNTs showed increased GFAP immunoreactivity compared to astrocytes on PDL (Fig. 4). Electrical stimulation neural activity is the basis of a number of technologies for the restoration of sensory or motor functions [32-35], brain-machine interfaces (BMI) [36, 37], deep brain stimulation therapies for neurological disorders [38], such as Parkinson's disease and depression. Metal electrodes are inadequate prospects for the miniaturization needed to attain neuronal-scale stimulation and recording because of their poor electrochemical properties, high stiffness, and propensity to fail due to bending fatigue. However, tissue contact impedance of 

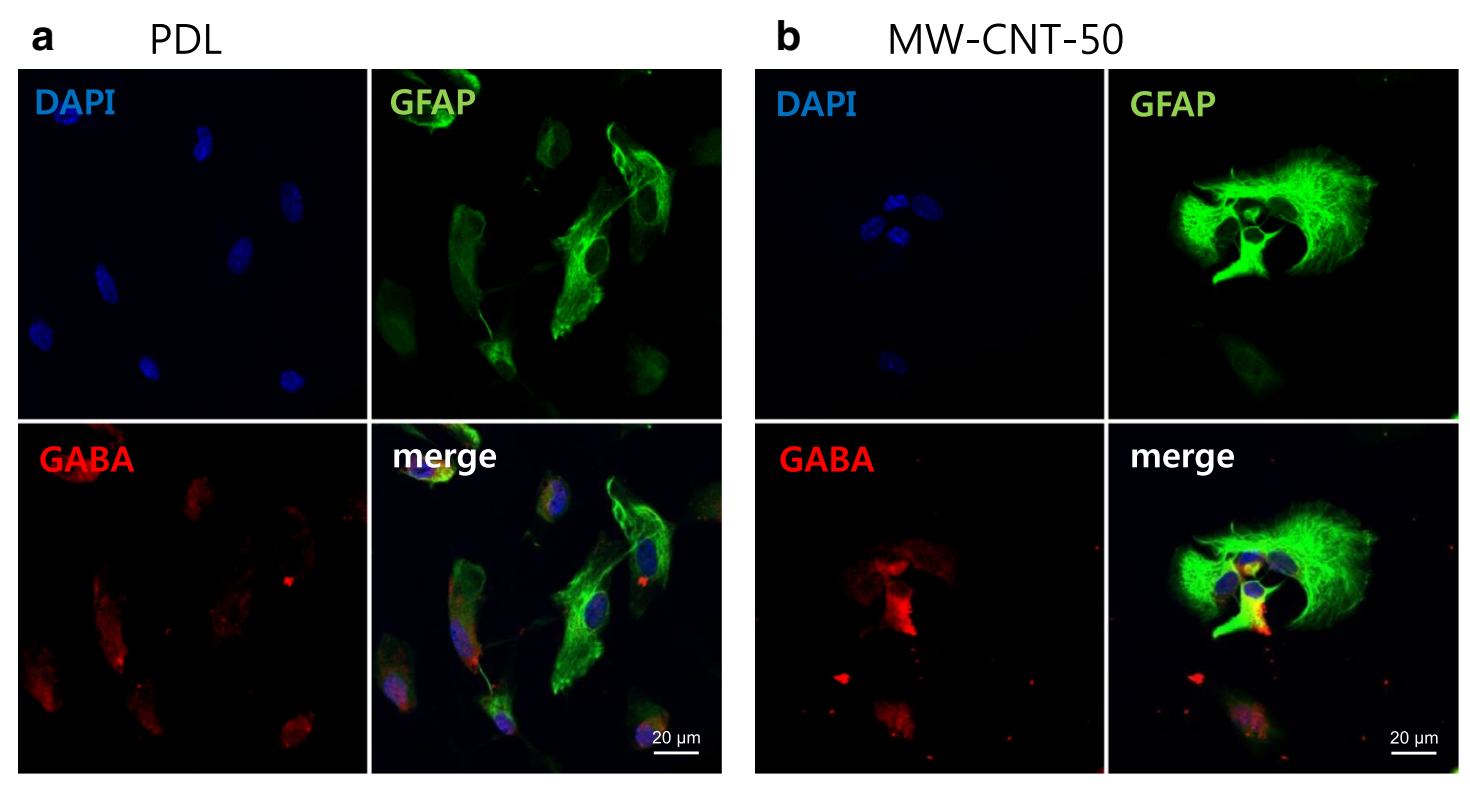

\section{c $\quad$ MW-CNT-1000}
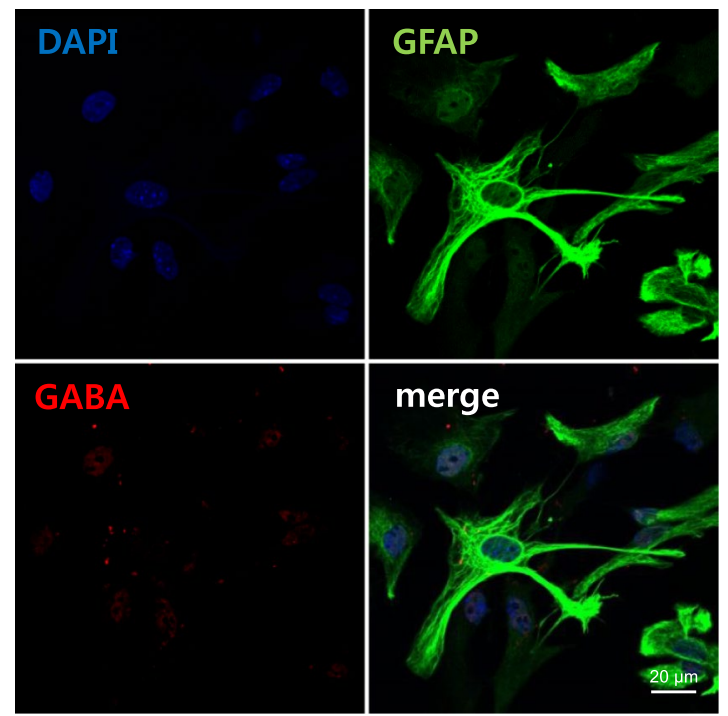

\section{d}

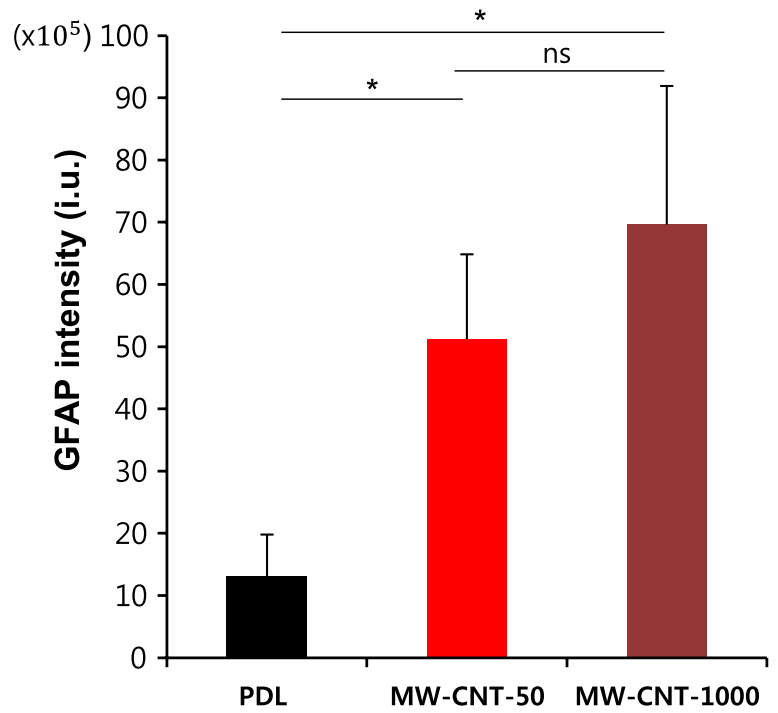

Fig. 4 Astrocytic GABA on MW-CNTs spreads into cell processes. a-c Immunostaining of GABA using anti-GABA (red), anti-GFAP (green) antibody in primary cortical astrocytes on MW-CNT and PDL coverslips. a shows distribution of astrocytic GABA near the nucleus. b shows astrocytes on MWCNT-50 to have a rounder shape compared to those on PDL and $\mathbf{c}$ shows distinct cell-cell interactions on MW-CNT-1000. a-c shows that intracellular GABA on MW-CNT has spread into cell processes (b, c) compared to the PDL coverslip (a); Scale bar $20 \mu \mathrm{m}$. d Graph shows MW-CNTs increase GFAP immunoreactivity compared to PDL ( $\left.{ }^{p} p<0.05\right)$; PDL $(n=7)$, MW-CNT-50 $(n=7)$, MW-CNT-1000 $(n=7)$. Fluorescence intensity (i.u.) $=$ cell intensity - (area $\times$ mean fluorescence of background)

CNT fibers is remarkably lower than that of state of the art metal electrodes, making them suitable for recording single-neuron activity [39]. Therefore, increased GFAP immunoreactivity on MW-CNTs have possibility for new therapy of neurodegenerative disorders and MW-CNTs can be a promise material for biocompatibility.

\section{Conclusion}

We expect that MW-CNTs of diverse length could be used efficiently in brain-machine interface technologies, for delivery of drugs to the brain in brain disease therapy because increased cell-cell interaction may reflect active communications between astrocytes and neurons. 
A recent study showed that single-walled CNTs modulate the morpho-functional and proliferative characteristics of astrocytes [22]. We confirmed that MW-CNTs also modulate intracellular morphology and proliferative characteristics such as an increased cell-cell interaction and the modulation of GABA distribution. CNTs look to be a promising material for use in varied fields, particularly in, brain-machine interface technologies, as they have been shown to efficiently stimulate neurons and have long-term stability, while eliciting a significantly reduced inflammatory response in Parkinsonian rodents [39]. Further studies are required to demonstrate astrocyte-neuron interactions with MW-CNTs, which may generate further advances in current brain disease therapy.

\section{Additional file}

Additional file 1: Figure S1-S3. Supplementary figures.

\section{Abbreviations}

MW-CNTs: multi-walled carbon nanotubes; PDL: poly-D-lysine; GABA: gammaamino butyric acid.

\section{Authors' contributions}

SYK prepared and characterized MW-CNT-50, 1000. JOM performed cytotoxicity test and immunocytochemistry. SYK and JOM performed scanning electron microscopy imaging. USS and BEY conceived the study participated in its design and coordination. JOM, USS and BEY wrote manuscript. All authors read and approved the final manuscript.

\section{Author details \\ 1 Department of Nanobiomedical Science and BK21 PLUS NBM Global Research Center for Regenerative Medicine, Dankook University, Dandae-ro, Dongnam-gu, Cheonan-si, Chungnam 330-714, Republic of Korea. ${ }^{2}$ Institute of Tissue Regeneration Engineering (ITREN), Dankook University, Dandae-ro, Dongnam-gu, Cheonan-si, Chungnam 330-714, Republic of Korea.}

\section{Acknowledgements}

The present research was conducted by the research fund of Dankook University in 2014.

\section{Compliance with ethical guidelines}

All experimental procedures described below were performed in accordance with the Dankook University Animal Experimentation Guidelines (Cheonan, Korea).

\section{Competing interests}

The authors declare that they have no competing interests.

Received: 19 August 2015 Accepted: 3 December 2015

Published online: 18 December 2015

\section{References}

1. Kateb B, Van Handel M, Zhang L, Bronikowski MJ, Manohara H, Badie B. Internalization of MWCNTs by microglia: possible application in immunotherapy of brain tumors. Neuro image. 2007;37(Suppl 1):S9-17.

2. Belyanskaya L, Weigel S, Hirsch C, Tobler U, Krug HF, Wick P. Effects of carbon nanotubes on primary neurons and glial cells. Neurotoxicology. 2009;30:702-11.
3. Salvador-Morales C, Flahaut E, Sim E, Sloan J, Green ML, Sim RB. Complement activation and protein adsorption by carbon nanotubes. Mol Immunol. 2006;43:193-201.

4. Ali Eatemadi HD, Karimkhanloo Hamzeh, Kouhi Mohammad, Zarghami Nosratollah, Akbarzadeh Abolfazl, Abasi Mozhgan, Hanifehpour Younes, Joo Sang Woo. Carbon nanotubes: properties, synthesis, purification, and medical applications. Nanoscale Res Lett. 2014;9:393.

5. Bellucci S, Gonzalez J, Onorato P. Crossover from the Luttinger-liquid to Coulomb-blockade regime in carbon nanotubes. Phys Rev Lett. 2005;95:186403.

6. Demczyk BG, Wang YM, Cumings J, Hetman M, Han W, Zettl A, Ritchie RO. Direct mechanical measurement of the tensile strength and elastic modulus of multiwalled carbon nanotubes. Mater Sci Eng, A. 2002;334:173-8.

7. Bekyarova E, Ni Y, Malarkey EB, Montana V, McWilliams JL, Haddon RC, Parpura V. Applications of carbon nanotubes in biotechnology and biomedicine. J Biomed Nanotechnol. 2005;1:3-17.

8. Malarkey EB, Parpura V. Applications of carbon nanotubes in neurobiology. Neuro-degenerative Dis. 2007;4:292-9.

9. Cellot G, Cilia E, Cipollone S, Rancic V, Sucapane A, Giordani S, Gambazzi L, Markram H, Grandolfo M, Scaini D, Gelain F, Casalis L, Prato M, Giugliano M, Ballerini L. Carbon nanotubes might improve neuronal performance by favouring electrical shortcuts. Nat Nanotechnol. 2009;4:126-33.

10. Malarkey EB, Fisher KA, Bekyarova E, Liu W, Haddon RC, Parpura V. Conductive single-walled carbon nanotube substrates modulate neuronal growth. Nano Lett. 2009;9:264-8.

11. Araque A, Parpura V, Sanzgiri RP, Haydon PG. Tripartite synapses: glia, the unacknowledged partner. Trends Neurosci. 1999;22:208-15.

12. Grosche J, Matyash V, Moller T, Verkhratsky A, Reichenbach A, Kettenmann $\mathrm{H}$. Microdomains for neuron-glia interaction: parallel fiber signaling to Bergmann glial cells. Nat Neurosci. 1999;2:139-43.

13. Fiacco TA, McCarthy KD. Astrocyte calcium elevations: properties, propagation, and effects on brain signaling. Glia. 2006;54:676-90.

14. Volterra A, Meldolesi J. Astrocytes, from brain glue to communication elements: the revolution continues. Nat Rev Neurosci. 2005;6:626-40.

15. Oliet SH, Mothet JP. Molecular determinants of D-serine-mediated gliotransmission: from release to function. Glia. 2006;54:726-37.

16. Xue $X$, Wang $L R$, Sato $Y$, Jiang $Y$, Berg $M$, Yang DS, Nixon RA, Liang XJ. Single-walled carbon nanotubes alleviate autophagic/lysosomal defects in primary glia from a mouse model of Alzheimer's disease. Nano Lett. 2014;14:5110-7.

17. Huang Y, Sudibya HG, Fu D, Xue R, Dong X, Li LJ, Chen P. Label-free detection of ATP release from living astrocytes with high temporal resolution using carbon nanotube network. Biosens Bioelectron. 2009;24:2716-20.

18. Lovat V, Pantarotto D, Lagostena L, Cacciari B, Grandolfo M, Righi M, Spalluto G, Prato M, Ballerini L. Carbon nanotube substrates boost neuronal electrical signaling. Nano Lett. 2005;5:1107-10.

19. Pastorin G. Carbon nanotubes: from bench chemistry to promising biomedical applications. Mater Today. 2011;14:290.

20. Mattson MP, Haddon RC, Rao AM. Molecular functionalization of carbon nanotubes and use as substrates for neuronal growth. J Mol Neurosci. 2000;14:175-82.

21. Hu H, Ni Y, Montana V, Haddon RC, Parpura V. Chemically functionalized carbon nanotubes as substrates for neuronal growth. Nano Lett. 2004:4:507-11.

22. Gottipati MK, Samuelson JJ, Kalinina I, Bekyarova E, Haddon RC, Parpura V. Chemically functionalized single-walled carbon nanotube films modulate the morpho-functional and proliferative characteristics of astrocytes. Nano Lett. 2013;13:4387-92.

23. Manoj K, Gottipati EB, Michael B, Robert CH, Vladimir P. Changes in the morphology and proliferation of astrocytes induced by two modalities of chemically functionalized single-walled carbon nanotubes are differentially mediated by glial fibrillary acidic protein. Nano Lett. 2014;14:3720-7.

24. Lee S, Yoon BE, Berglund K, Oh SJ, Park H, Shin HS, Augustine GJ, Lee CJ. Channel-mediated tonic GABA release from glia. Science. 2010;330:790-6.

25. Lee SH, Kim WT, Cornell-Bell AH, Sontheimer H. Astrocytes exhibit regional specificity in gap-junction coupling. Glia. 1994;11:315-25.

26. Dermietzel R, Spray DC. Gap junctions in the brain: where, what type, how many and why? Trends Neurosci. 1993;16:186-92.

27. Loewenstein WR. Junctional intercellular communication: the cell-to-cell membrane channel. Physiol Rev. 1981;61:829-913. 
28. Elder AC, Gelein R, Azadniv M, Frampton M, Finkelstein J, Oberdorster G. Systemic effects of inhaled ultrafine particles in two compromised, aged rat strains. Inhal Toxicol. 2004;16:461-71.

29. Oberdorster G, Sharp Z, Atudorei V, Elder A, Gelein R, Kreyling W, Cox C. Translocation of inhaled ultrafine particles to the brain. Inhal Toxicol. 2004; 16:437-45.

30. Barres BA. The mystery and magic of glia: a perspective on their roles in health and disease. Neuron. 2008;60:430-40.

31. Sofroniew MV. Reactive astrocytes in neural repair and protection. Neuroscientist. 2005;11:400-7.

32. Schultz AE, Kuiken TA. Neural interfaces for control of upper limb prostheses: the state of the art and future possibilities. PM\&R. 2011;3:55-67.

33. Hadjinicolaou AE, Leung RT, Garrett DJ, Ganesan K, Fox K, Nayagam DA, Shivdasani MN, Meffin H, Ibbotson MR, Prawer S, O'Brien BJ. Electrical stimulation of retinal ganglion cells with diamond and the development of an all diamond retinal prosthesis. Biomaterials. 2012;33:5812-20.

34. Collinger JL, Wodlinger B, Downey JE, Wang W, Tyler-Kabara EC, Weber DJ, McMorland AJ, Velliste M, Boninger ML, Schwartz AB. High-performance neuroprosthetic control by an individual with tetraplegia. Lancet. 2013;381:557-64.
35. Anderson DJ. Penetrating multichannel stimulation and recording electrodes in auditory prosthesis research. Hear Res. 2008;242:31-41.

36. O'Doherty JE, Lebedev MA, Ifft PJ, Zhuang KZ, Shokur S, Bleuler H, Nicolelis MA. Active tactile exploration using a brain-machine-brain interface. Nature. 2011;479:228-31.

37. Fitzsimmons NA, Drake W, Hanson TL, Lebedev MA, Nicolelis MA. Primate reaching cued by multichannel spatiotemporal cortical microstimulation. J Neurosci Off J Soc Neurosci. 2007;27:5593-602.

38. Lozano AM, Dostrovsky J, Chen R, Ashby P. Deep brain stimulation for Parkinson's disease: disrupting the disruption. Lancet Neurol. 2002;1:225-31.

39. Vitale F, Summerson SR, Aazhang B, Kemere C, Pasquali M. Neural stimulation and recording with bidirectional, soft carbon nanotube fiber microelectrodes. ACS Nano. 2015;9:4465-74.

\section{Submit your next manuscript to BioMed Central and we will help you at every step:}

- We accept pre-submission inquiries

- Our selector tool helps you to find the most relevant journal

- We provide round the clock customer support

- Convenient online submission

- Thorough peer review

- Inclusion in PubMed and all major indexing services

- Maximum visibility for your research

Submit your manuscript at www.biomedcentral.com/submit

() Biomed Central 